\title{
Is it better to treat bypass graft or native coronary artery following early graft failure?
}

\author{
Davorin Sef $^{1}$, Mladen Predrijevac ${ }^{2}$, Shahzad Raja ${ }^{1}$, and Marko Turina ${ }^{3}$ \\ ${ }^{1}$ Royal Brompton and Harefield NHS Foundation Trust \\ ${ }^{2}$ Magdalena - Clinic for Cardiovascular Diseases \\ ${ }^{3}$ University Hospital Zurich
}

October 12,2020

\begin{abstract}
Several studies have already shown that coronary angiography and PCI can be safely performed after CABG. It is of paramount importance that early graft failure is recognized in a timely manner and that an appropriate treatment is delivered immediately in order to reduce the extent of myocardial damage and improve clinical outcome. Therefore, urgent angiography allows both identification of the underlying cause of early graft failure and immediate treatment according to the findings. So far, recent evidence shows that PCI to native coronary arteries is associated with higher procedural success rate and less complications leading to the better clinical outcome.
\end{abstract}

Is it better to treat bypass graft or native coronary artery following early graft failure?

Davorin Sef ${ }^{1}$, Mladen Predrijevac ${ }^{2}$, Shahzad G. Raja ${ }^{1}$, Marko I. Turina ${ }^{3}$

${ }^{1}$ Department of Cardiac Surgery, Royal Brompton and Harefield NHS Foundation Trust, Harefield Hospital, London, UK

${ }^{2}$ Department of Cardiac Surgery, Magdalena - Clinic for Cardiovascular Diseases, Krapinske Toplice, Croatia

${ }^{3}$ University of Zurich, Zurich, Switzerland

Conflict of Interest: The authors have declared no conflicts of interest for this article.

Key words: graft failure, coronary artery bypass surgery, percutaneous coronary intervention, coronary artery disease.

Word count: 1081

Correspondence :

Dr. Davorin Sef

Department of Cardiac Surgery

Royal Brompton \& Harefield NHS Foundation Trust,

Harefield Hospital,

Hill End Road, UB96JH London, UK

Tel: +441895828715, E-Mail: davorin.sef@gmail.com

Main Text 
Patients with early graft failure after coronary artery bypass grafting (CABG) still present one of the major clinical challenges in cardiac surgery. Early postoperative graft failure carries a high morbidity and mortality in patients undergoing CABG $[1,2]$. Available data suggest that arterial grafts, including left internal thoracic artery (LITA), right internal thoracic (RITA) and radial artery, provide superior angiographic patency rates when compared with saphenous vein grafts (SVGs) [3]. Unfortunately, vein graft failure can occur in up to $25-40 \%$ of patients within the first year and is associated with an increased risk of adverse events [4, 5]. On the other hand, failure of the LITA-to-left anterior descending artery (LAD) is a rare event [6]. Many trials have established a clear advantage of LITA-to-LAD in terms of survival and freedom from re-intervention [3, 7]. Despite the limited long-term patency, autologous SVG remains a frequently used conduit even in the case of grafting the LAD $[8,9]$. In one of the recent studies about outcomes percutaneous coronary interventions (PCI) on different bypass grafts following failure of the graft to the LAD, it was demonstrated that most patients (67.6\%) had SVG-to-LAD graft failure as compared to the LITA graft and, in our opinion, the reported frequent use of SVG does not reflect the contemporary cardiac surgical practice [8]. However, there are still some doubts whether the better patency rate of arterial grafts provides potential clinical benefits in most patients undergoing CABG. It is expected that a large randomized trial with the analysis of the arterial grafts (ROMA [Randomized Comparison of the Clinical Outcome of Single Versus Multiple Arterial Grafts]) could provide the results in a few years' time [10].

Different treatment options are available to manage early graft failure including PCI, reoperation and conservative management [11]. We have also proposed an algorithm for managing CABG patients with suspected early postoperative MI and early graft failure (Figure 1).Early postoperative mortality among patients with early graft failure who underwent redo-CABG is increased in comparison with PCI $[2,12,13]$. In addition, a recent study by Sharma et al. showed that patients presenting with postoperative MI clearly had the highest incidence of acute graft failure and revascularization via PCI amongst other subgroups, suggesting that they were more likely to have underlying treatable myocardial ischemia [14]. On the other hand, patients with significant postoperative haemodynamic compromise due to suspected early graft failure obviously need emergent reoperation for potential correction. According to the current guidelines, PCI is the preferred revascularization strategy in patients with early graft failure and amenable anatomy, with procedural success rate up to $93 \%[2,8,15]$, and has the potential to limit the extent of MI [15, 16]. Moreover, a report from the National Cardiovascular Data CathPCI Registry showed that patients with prior CABG represent up to $17.5 \%$ of all patients undergoing PCI [17]. On the other hand, operative mortality after redo-CABG is increased two-fold to four-fold when compared with the first time CABG, therefore the indications here remain relatively strict [18]. Consequently, redo-CABG should be favoured only if the anatomy is unsuitable for PCI, if several important grafts are occluded, or in the case of obvious anastomotic errors [15]. In our opinion, reopening of the anastomosis is a faulty step and is dangerous; much safer option is additional vein graft distal to the anastomosis. This covers both local problems at the anastomosis (dissection, faulty suturing) and poor ITA/graft flow [2].Another key consideration in optimizing outcomes following CABG can be documentation of graft patency intraoperatively. An objective intraoperative assessment of bypass grafts using transit time flow meter measurements can serve as an important quality indicator in contemporary CABG surgery [15]. Recent evidence shows that high pulse index value is a risk factor for early graft failure independently of different target territories [19].

There is still limited data about comparison of outcomes of patients with early graft failure who had PCI to either native coronary arteries or SVGs. Currently, it is recommended that PCI via the bypassed native coronary artery should be the preferred approach [18]. However, if PCI in the native coronary artery fails or does not seem as an option, PCI in the SVG should be considered [18]. Furthermore, recent evidence shows that PCI to the SVG is less efficient when compared to the PCI of native coronary arteries, and is associated with lower procedural success rate, higher rate of complications, and inferior long-term outcomes (mortality, MI) [9, 20]. Graft interventions are known to be generally more complex as LIMA graft especially has tendency to dissect while SVG has a risk of distal embolization, frequently resulting in periprocedural MI [15]. However, the decision to perform PCI to either native coronary artery or the SVG depends on many factors, such as complexity of the coronary artery disease, graft-related and operator-related factors. 
In summary, several studies have already shown that coronary angiography and PCI can be safely performed after CABG. It is of paramount importance that early graft failure is recognized in a timely manner and that an appropriate treatment is delivered immediately in order to reduce the extent of myocardial damage and improve clinical outcome. Therefore, urgent angiography allows both identification of the underlying cause of early graft failure and immediate treatment according to the findings. So far, recent evidence shows that PCI to native coronary arteries is associated with higher procedural success rate and less complications leading to the better clinical outcome.

\section{REFERENCES}

1. Davierwala PM, Verevkin A, Leontyev S, et al. Impact of expeditious management of perioperative myocardial ischemia in patients undergoing isolated coronary artery bypass surgery. Circulation. 2013;128(11 Suppl 1):S226-34.

2. Sef D, Szavits-Nossan J, Predrijevac M, et al. Management of perioperative myocardial ischaemia after isolated coronary artery bypass graft surgery. Open Heart. 2019 May; 8;6(1):e001027.

3. Gaudino M, Bakaeen FG, Benedetto U, et al. ATLANTIC (Arterial Grafting International Consortium) Alliance members. Arterial Grafts for Coronary Bypass: A Critical Review After the Publication of ART and RADIAL. Circulation. 2019 Oct 8;140(15):1273-1284.

4. Magee MJ, Alexander JH, Hafley G, et al. Coronary artery bypass graft failure after on-pump and off-pump coronary artery bypass: findings from PREVENT IV. Ann Thorac Surg. 2008;85(2):494-9; discussion 499-500.

5. Hess, CN, Lopes RD, Gibson CM, et al. Saphenous vein graft failure after coronary artery bypass surgery: insights from PREVENT IV. Circulation 2014;130(17):1445-51.

6. Hlatky MA, Shilane D, Boothroyd DB, et al. The effect of internal thoracic artery grafts on long-term clinical outcomes after coronary bypass surgery. J Thorac Cardiovasc Surg. 2011;142(4):829-35.

7. Raja SG. Total arterial off-pump coronary revascularization: The Holy Grail? Curr Opin Cardiol. 2019 Sep;34(5):552-556.

8. Yeo KK, Azarbal F, Zakroysky P, et al. Differential Longitudinal Outcomes Following Percutaneous Coronary Intervention to the Left Internal Mammary Artery and Other Bypass Grafts of the LAD: Findings From the NCDR. J Invasive Cardiol. 2020 Jun;32(6):E143-E150.

9. Shoaib A, Johnson TW, Banning A, et al. Clinical Outcomes of Percutaneous Coronary Intervention for Chronic Total Occlusion in Native Coronary Arteries vs Saphenous Vein Grafts. J Invasive Cardiol, 2020 Aug 10;

10. Gaudino M, Alexander JH, Bakaeen FG, et al. Randomized comparison of the clinical outcome of single versus multiple arterial grafts: the ROMA trial-rationale and study protocol. Eur J Cardiothorac Surg. 2017;52(6):1031-1040.

11. Levine S, Mendoza CE, Virani SS, et al. Rescue percutaneous coronary intervention for graft failure immediately after coronary artery bypass grafting: case report and review of literature. J Card Surg. 2008;23(6):709-712.

12. Locker C, Greiten LE, Bell MR, et al. Repeat Coronary Bypass Surgery or Percutaneous Coronary Intervention After Previous Surgical Revascularization. Mayo Clin Proc. 2019;94(9):1743-1752.

13. Weintraub WS, Jones EL, Morris DC, King SB, Guyton RA, Craver JM, et al. Outcome of reoperative coronary bypass surgery versus coronary angioplasty after previous bypass surgery. Circulation. 1997;95(4):868-77.

14. Sharma V, Chen K, Alansari SA, Verma B, Soltesz E, Johnston D, et al. Outcomes of early coronary 
angiography or revascularization after cardiac surgery. Ann Thorac Surg. 2020 Sep 15:S0003-4975(20)314752. doi: 10.1016/j.athoracsur.2020.06.113.

15. Neumann FJ, Sousa-Uva M, Ahlsson A, et al. [2018 ESC/EACTS Guidelines on myocardial revascularization. The Task Force on myocardial revascularization of the European Society of Cardiology (ESC) and European Association for Cardio-Thoracic Surgery (EACTS)]. G Ital Cardiol (Rome). 2019;20(7-8 Suppl 1):1s-61s.

16. Hillis LD, Smith PK, Anderson JL, et al. 2011 ACCF/AHA Guideline for Coronary Artery Bypass Graft Surgery: a report of the American College of Cardiology Foundation/American Heart Association Task Force on Practice Guidelines. Circulation. 2011;124(23):e652-735.

17. Brilakis ES, Rao SV, Banerjee S, et al. Percutaneous coronary intervention in native arteries versus bypass grafts in prior coronary artery bypass grafting patients: a report from the National Cardiovascular Data Registry. JACC Cardiovasc Interv. 2011;4(8):844-50.

18. Neumann FJ, Sousa-Uva M, Ahlsson A, et al. [2018 ESC/EACTS Guidelines on myocardial revascularization]. Kardiol Pol. 2018;76(12):1585-1664.

19. Zhang G, Zhao Z, Han Z, Gao Q, Liu J, Chen Y.The predictive value of intraoperative transittime flow measurement parameters for early graft failure in different target territories. J Cardiol.2020 Oct 1:S0914-5087(20)30308-7. doi: 10.1016/j.jjcc.2020.09.003.

20. Brilakis ES, O'Donnell CI, Penny W, et al. Percutaneous Coronary Intervention in Native Coronary Arteries Versus Bypass Grafts in Patients With Prior Coronary Artery Bypass Graft Surgery: Insights From the Veterans Affairs Clinical Assessment, Reporting, and Tracking Program. JACC Cardiovasc Interv. 2016;9(9):884-93.

\section{FIGURE LEGENDS.}

FIGURE 1. Proposed algorithm for managing patients with suspected early postoperative myocardial infarction and early graft failure following coronary artery bypass graft surgery. ECMO, extracorporeal membrane oxygenation; HD, hemodynamically; IABP, intra-aortic balloon pump; Redo-CABG, defined as an additional vein graft distal to the anastomosis. 


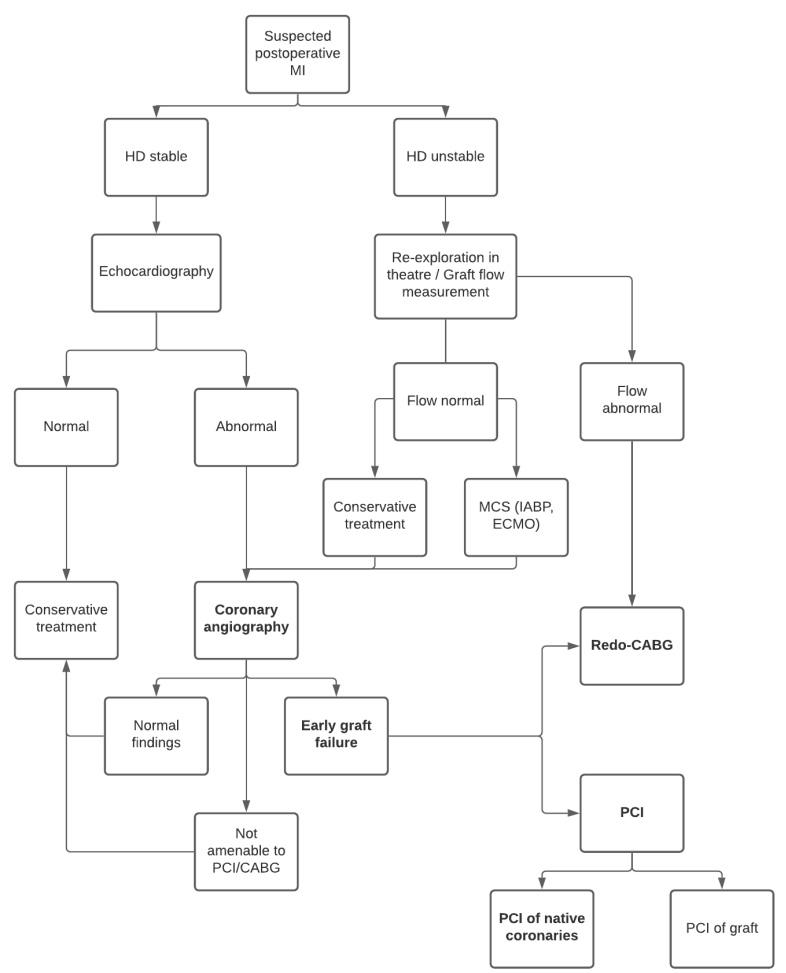

